\title{
MAPs in Sicily: Cultivation, Uses and Potentiality
}

\author{
A. Carrubba, M. Militello and C. Catalano \\ DSAGA - Department of Agro-Environmental Systems \\ University of Palermo \\ Palermo \\ Italy
}

Keywords: Mediterranean environments, multifunctional agriculture, biodiversity, natural products, cropping techniques

\begin{abstract}
In Sicily, MAPs have been used and cultivated for centuries, with many uses ranging from the preparation of fresh or stored food items, flavoring of foods and beverages, home-made human or animal therapy or even aesthetical purposes. Many of them grow spontaneously and are claimed to play a significant role in land biodiversity. The widespread belief that only under natural conditions can MAPs find their optimum quality features has driven many cases of uncontrolled collection from the wild, as a result many of them are nowadays at a risk of extinction. The field cropping of such spontaneous species could play an important role in safeguarding biodiversity. It could also help in solving some of the major land-use problems, giving raw matters and intermediate products dealing with a significant economic value to many productive sectors, even external to agriculture. Much work has already been done in this direction, but much work is still to do. More resources and combined efforts are required in order to explore the genetic variability inside those plants and to choose, for each plant or plants group, the most suitable cropping technique.
\end{abstract}

\section{INTRODUCTION}

In Sicily, dealing with about $26.000 \mathrm{~km}^{2}$ in extension, more than 2650 specific and infraspecific taxa were counted (Raimondo et al., 1992). In the early 1960s, Bruno et al. (1960), pointed at 114 species, mostly herbaceous, as the most representative MAPs inside Sicilian flora. Further studies (Lentini, 2000; Lentini and Venza, 2007; Raimondo and Lentini, 1990; Raimondo and Venturella, 1993) have allowed us to identify with better detail the flora of many small areas inside the region, stating the occurrence of many valued MAPs. Many of them grow spontaneously into such areas and are claimed to play a significant role inside land biodiversity (Carrubba, 2010).

The use of MAPs in Sicily deals with a long history and many of them have been used and cultivated for centuries for plenty of purposes, from the flavoring of foods and beverages to the treatment of many human and animal diseases (Lentini, 2000). Traditionally, their major source is the collection from the wild and such an activity is not ruled by any regional law, except for the areas that are classed among Parks or Natural Reserves (R.L. 98/81 and R.L. 14/88). Due to their generally low demand, the uncontrolled collection from the wild has been satisfactory for centuries. Nowadays many conditions have changed and a greater attention is paid to some sustainable alternative to this practice. The first thing to consider is that market demand has changed and there is a growing necessity to guarantee a continuous supply for industry, supposed to be constant both for quantity and for quality. Second, the field cropping of such spontaneous species could play an important role in safeguarding biodiversity (Schippmann et al., 2002) and could also help in solving some of the major land-use problems, giving raw matters and intermediate products dealing with a significant economic value to many productive sectors even external to agriculture (Carrubba, 2010; Carrubba et al., 2008).

A considerable land area in Sicily faces many of the problems which are typical of developing countries, without any acknowledgement of this status. Many factors are involved in determining this marginality condition, such as soil and climatic features 
(limiting levels of temperature and moisture, somewhere salinity, excess of clay in soils, adverse conditions of soil depth, $\mathrm{pH}$ level, texture and orography), but also social and economical traits such as the small size of farms and the high incidence of fixed costs (Carrubba and Catalano, 2009).

In those environments, considered to be fragile ecosystems, it is generally not adviceable following the commonly adopted cropping techniques, neither the choice of the common cash crops is generally possibile. It is particularly important, therefore, to study and point out new cropping system models, which must be manageable, applying the most conservative and environmentally-friendly methods.

\section{CULTIVATION OF MAPs}

In developed countries, MAPs play the same role as the most important industrial crops and many areas in which they are largely cultivated get most of their income from them (Lavender in France, Saffron in Spain and so on).

Today, the studies about many species have reached a good deepening level and for many plants it is possible to define the main GAPs (Good Agricultural Practices) spanning from sowing to harvest, sometimes also providing information about the steps of post-harvest processing. Notwithstanding, the cultivation of MAPs is not always an easy task. Some Authors (McConnell and Anderson, 2002) consider these plants as "weedy" species, assigning them the important aptitude to allow better productions under low fertility conditions, without any significant yield raise as the fertility conditions increase. It is true that many aspects of cropping technique exert on MAPs production rather different effects than in most other crops. $\mathrm{N}$ fertilization and irrigation, as an example, are thought to increase biomass yield in many species, but in some cases they have shown negative effects on the biosynthesis and composition of essential oils; e.g. in oregano, that is cultivated to obtain the inflorescences, the market end value depends on flowers scent and aroma, that on their turn are based upon the quantity of essential oils and the relative abundance of aromatic phenols inside them.

An additional complication is that, nevertheless breeding and genetic amelioration, many MAPs still bear plant traits that belong to the wild rather than to the cultivated species; those traits are the result of millennia of evolution and typically plant evolution doesn't keep the needs of man and agriculture in consideration. Although cultivation practices may do a lot in order to lower their outcome on yields, often such traits are maintained even under cropping conditions and somehow they make the major cropping operations (such as mechanization) more difficult. One of them is the indeterminate growth habit, that is the reason why plants go on producing flowers and fruits continuously. Another one is fruit dehiscence, that is a consequence of the plant adaptative mechanism which promote dissemination. Both these features exert an influence on harvest management, making this operation harder. Hence, mechanization is, above all for harvest, one of the major constraints (even if not the only one) in MAPs cultivation and this is the main reason why harvest is often performed by means of very expensive manual interventions.

Furthermore, MAPs have very often a reduced competitivity level against weeds. Weeds are generally very well fitted to their ecological role, show a great resistance and aggressivity, a very quick biological cycle that closes within the biological cycle of the major crops and a remarkable development rate expecially in the starting phases, that generally fall when cultivated MAPs are more delicate and fragile.

All these problems must not be underestimated; probably due to their low aptitude to behave as the usual "cash" crops, the cultivation of a few MAPs with an interesting profitability is often thought to represent an important tool for a rational and sustainable exploitation of many marginal environments.

In many areas of Sicily, as in most Mediterranean lands, the production of many native MAPs should find very favourable conditions (Carrubba, 2010; Franz, 1996). Currently, MAPs are cultivated by 1.598 farms on 241 ha, and this puts Sicily at the first place among Italian regions for number of farms and at the second for invested area. 
Farms cultivating MAPs lie above all $(94,6 \%)$ on hilly areas, whereas only $1,7 \%$ of farms (with 5,2\% of invested area) are located in mountain and plain zones (Di Franco, 2007). In 2000, most of regional MAPs area was found above all in the provinces of Messina and Trapani (in the coastal area), whereas some years later (2007) it moved into the inner territories between Caltanissetta and Agrigento (Migliore and Saggio Scaffidi, 2007). A somewhat constant observation is that the areas involved are rather small, since in the majority of cases farms have an average extension lower than 2 ha. From here they encounter some of the local difficulties of this cultivation, leading to a vary small market supply and in absence of associationism, also to an unsatisfactory market management of productions. Short chain is rather absent and there is no linkage between the producers and the transformation industry is detectable. About $45 \%$ of farms sell their product to wholesalers, who on their turn sell to the industry and large-scale organized distribution; in $36 \%$ of cases, the producers package their products and sell them to co-operatives $(18 \%)$ or have some connection with restaurants $(18 \%)$, in a few cases $(9 \%)$ they sell to shopkeepers and only $6 \%$ to laboratories for cosmetic or herbal manufacturing. Most of the products are sold on the regional market $(64 \%)$, only $21 \%$ on the national market and $15 \%$ on the foreign market.

Most of MAPs cultivation in Sicily is performed by applying rather extensive and low-labour farming systems, in this resembling the cropping management that is mostly performed in developing countries. Inside farms, a distinction may be performed between perennial and annual species; those belonging to the first group are cultivated outside crop rotation, whereas the others fit inside the usual farm rotation. In the first case, crops stand on the same area for 4-5 to 10 consecutive years, according to cropping conditions and fertility level of the soils. Unlike the others, they normally require a good fertilization supply (that in organic is often represented by a good manure distribution) at the beginning of cultivation and reduced interventions throughout the subsequent years.

Plantation is usually performed by transplant; with respect to direct sowing, this technique allows a more uniforme settling of crops, expecially with a low soil moisture content, and a higher competitivity level against weeds, above all in the starting phases of crop settlement.

Annuals have, with respect to the others, the significant advantage to give farmers a higher opportunity to conform quickly to the changes of market needs. Their cropping cycle closes in some months or so after sowing and therefore they fit inside the commonest farm rotations. Some of them (such as coriander, fennel or chamomile) require a rather simple cropping technique: the major cropping operations (sowing, weeding, and harvest) may be performed mechanically and in most cases they don't need any modification of the machinery commonly used in the majority of farms. In spite of this, the largest quantity of MAPs-growing farms in Sicily is oriented towards perennials such as Oregano, that covers about $70 \%$ of the whole land area invested with MAPs.

\section{Organic Production}

Organic production is certainly a strong point for MAPs cultivation in Sicily. As a matter of fact, MAPs can take more advantage than many other crops from such a cropping method, since organic cropping management (and labelling) offers to them the opportunity to strenghten the perception of "naturality" that is often associated with them, hence gaining on higher market prices. Many European consumers now expressely require that herbs are produced by the organic method, in the belief that it confers to products a higher health value and some MAPs manufacturers have started setting special organic production lines (ITC, 2006).

In Sicily, about $70 \%$ of the area invested with MAPs is managed by the organic method. A microeconomical farm surveys shows that such a method allows to gain a supplementary mean gross income of about 2.600 euros per year, per hectare compared to conventional management, mainly due to the higher market value of organic products. It is however true that sharing of costs in organic management is rather different from conventional conditions and many practices require, with organic management, a higher 
expertise level. The highest income is found in all farms where the product is sold with some degree of transformation, with the possibility to gain an additional payment that otherwise would be taken from other players in the supply chain (Migliore and Saggio Scaffidi, 2007).

\section{USES OF MAPs}

Medicinal and aromatic plants (MAPs) are largely used in Sicily, both for fresh consumption and for a large number of domestic utilizations, including seasoning of foods and human and animal phytotherapy. Although many plants are used also for other uses, a useful distinction may be made between medicinal and aromatic uses.

\section{Medicinal Plants}

Medicinal plants are commonly used in traditional therapy in many areas of the world. An important push towards the research about them is coming from ethnopharmacology, that is the study of medicines used by traditional communities. Many investigations have been carried out in Sicily in this directions and many plants have been pointed out as potentially interesting items (Amico and Sorce, 1997; Lentini, 2000). For example, Milk Thistle (Silybum marianum Gaertn.) is a native plant from Asteraceae that bears a great interest in order to extract silymarin, an organic complex that is not yet possible to synthesize, which is largely used to treat a few liver diseases (Abenavoli et al., 2010). Another example is St. John's Wort (Hypericum spp.), that is traditionally used in Sicily as a popular remedy for burns and wounds. Many species belonging to the genus Hypericum (H. hircinum, H. perforatum, $H$. perfoliatum) have been reported in Sicily (Pignatti, 1982), all of them are collected for producing a special oil used for these purposes and the absence of the official data of areas invested with Hypericum (Vender, 2001; Migliore and Saggio Scaffidi, 2007) allows to think that all of the used material comes from wild collections.

\section{Aromatic Plants}

Although nowadays many aromatic plants are cultivated for the extraction of the essential oils, in Sicily most of them are still used as fresh herbs or to prepare a few traditional courses. Among these, oregano is the best known, but many other are used such as sage, rosemary, thyme, laurel and fennel. Much interest is devoted to rosemary, and its many utilizations allow to consider this species as a very good example of multifunctional species (Carrubba, 2010). Rosemary's plant is a commercial item per se, but it may also be subjected to many transformation processes having various levels of complexity, such as drying, grinding or distillation and may represent the starting material for the preparation of liqueurs, perfumes and extracts for antioxidant and preservative activity, even dehydorated. Furthermore, the plant has also good potentialities for bee attraction, in this deserving good attention for honey production.

\section{Plants for Other Uses}

Besides their many classical uses, there are many plants inside Sicilian flora that are devoted to many different folk utilizations; a plenty of them (about 30 taxa, including many Brassicaceae, Asteraceae, Apiaceae and Labiatae), are used as food, raw or cooked, but it is worth to notice that their use, once very common in certain areas, is currently declining due to the urbanization and globalization of eating habits (Lentini and Venza, 2007). Other utilizations may also be mentioned, such as the extraction of dyes (Rubia tinctorum L., Isatis tinctoria L.) or tannins (Rhus coriaria L.).

\section{POTENTIALITY}

There is room in Sicily for an expansion of cultivation and marketing of MAPs. The main reason is that they are able to integrate in a synergistic way with all the initiatives for rural development inside the area, giving farmers an important opportunity for income diversification and in the meantime, sustaining the use of resources, 
safeguarding biodiversity and also maintaining important linkages with manufacturing and touristic concerns. The factors that represent constraints to this development are to be searched above all in some structural penalties linked to commercial limits originated by the small economical size of farms. Probably, this problem could be partially solved by means of the concentration inside the farm of more segments of the production chain; this could allow the farmer to get a higher income due to the higher degree of transformation of the product, so exploiting the possibility of integration belonging to this special activity. Of course a high level of expertise is needed for farmers and a better organization of production activity, with a larger recourse to cooperation and associationism, could be important in this sense.

Due to a scarce visibility on markets, MAPs can't face the concurrence from other products coming in very large amounts and at cheap prices from other parts of the world. A well planned marketing policy should be encouraged, also promoting all the production methods (such as the organic ones) able to enhance the naturality features of herbal products.

\section{CONCLUSIONS}

Multifunctionality and diversification of farming systems, integration of agricultural practices both inter se and with the outer productive systems operating on the territory, safeguard of biodiversity and reduction of off-farm inputs, are the keywords for every modern development strategy for agricultural areas. Such an issue is valid worldwide, but it is especially true in all those areas in which the cultivation of the more widespread and classical crops are somehow constrained. In Mediterranean areas, where many environmental and economic factors often push rural areas to marginality conditions, the search for new crop opportunities has become one of the newest topics in agricultural research.

The major points of our analysis are the following:

1) Growing MAPs as specialized cultivations, especially for species native to the Mediterranean environments, is the only practical and sustainable way to obtain naturally-derived raw matter for industrial but also domestic purposes.

2) Most essential oil crops are suitable for many different uses and re fully adaptable to be transformed even by small, local manufacturers.

3) In many cases, they may be grown with environmentally friendly or organic techniques; this enhances their environmental compatibility and also gives them an additional economical advantage, raising their chances to be addressed to the emerging market sector of natural products.

Our conclusion is that such crops may be a strategic resource and there is scope for farmers to improve their cultivation on arable land. Many agronomical and economic questions are however to be studied in future experimentation and research and more resources and combined efforts are required in order to explore the potentialities of those plants.

\section{Literature Cited}

Abenavoli, L., Capasso, R., Milic, N. and Capasso, F. 2010. Milk Thistle in liver diseases: Past, present, future. Phytother. Res. 24:1423-1432.

Amico, F.P. and Sorce, E.G. 1997. Medicinal plants and phytotherapy in Mussomeli area (Caltanissetta, Sicily, Italy). Fitoterapia LXVIII:143-159.

Bruno, F., Di Martino, G. and Bonomo, F. 1960. Le piante officinali spontanee della Sicilia e dell'arcipelago delle Pelagie. Lav. Ist. Bot. e Giard. Colon. di Palermo XVII:131-251.

Carrubba, A. 2010. Sustainability and multifunctionality in Mediterranean cropping systems: the role of medicinal and aromatic plants. p.813-823. In: F. Trapani and G. Ruggeri (eds.), Proc. 3rd IRT Int. Sci. Conf. Integrated Relational Tourism Territories and Development in the Mediterranean Area, Helwan (Egypt), 24-26 October 2009. 
Carrubba, A. and Catalano, C. 2009. Essential oil crops for sustainable agriculture - a review. p.137-188. In: E. Lichtfouse (ed.), Climate Change, Intercropping, Pest Control and Beneficial Microorganisms. Springer, Dijon.

Carrubba, A., Catalano, C. and Bontempo, R. 2008. Multifunctional role of medicinal and aromatic plants: perspectives and constraints. Italian Journal of Agronomy 3 Suppl. 3:439-440.

Di Franco, C.P. 2007. La coltivazione di piante officinali in Italia e in Sicilia: produzione e mercato. p 45-68. In: M. Crescimanno (ed.), Le Piante Officinali in Sicilia. Potenzialità di Sviluppo della Coltivazione con Metodo Biologico. Università degli Studi di Palermo, Dip. di Economia dei Sistemi Agroforestali, Palermo (In Italian).

Franz, Ch. 1996. Significant Medicinal and Aromatic Plants to be cultivated in the Mediterranean region. Proc. Int. Congr. Coltivazione e miglioramento di piante officinali - Trento (Italy), 2-3 June 1994. p.239-250.

ITC (International Trade Centre), UNCTAD/WTO. 2006. Marketing Manual and Web Directory for Organic Spices, Culinary Herbs and Essential Oils. $2^{\text {nd }}$ Edition. Geneva, Switzerland $52 \mathrm{p}$.

Lentini, F. 2000. The role of ethnobotanics in scientific research. State of ethnobotanical knowledge in Sicily. Fitoterapia 71:S83-S88.

Lentini, F. and Venza, F. 2007. Wild food plants of popular use in Sicily. Journal of Ethnobiology and Ethnomedicine 3:15.

McConnell, J. and Anderson, S. 2002. Micronutrients for coriander and dill; macronutrients for coriander, dill, and caraway. In: Spoke Program Research Report, Saskatchewan Agriculture and Food p.175-176.

Migliore, G. and Saggio Scaffidi, C. 2007. La filiera delle piante officinali in Sicilia. p.75-116. In: M. Crescimanno (ed.), Le Piante Officinali in Sicilia. Potenzialità di Sviluppo della Coltivazione con Metodo Biologico. Università degli Studi di Palermo, Dip. Di Economia dei Sistemi Agroforestali, Palermo (In Italian).

Pignatti, S. 1982. Flora d'Italia - Vol. I, Edagricole, Bologna, Italy. p.343-351 (In Italian).

Raimondo, F.M., Gianguzzi, L. and Ilardi, V. 1992. Inventario delle specie 'a rischio' nella flora vascolare della Sicilia. Quaderni Botanica Ambientale Applicata 3:65-132 (In Italian).

Raimondo, F.M. and Lentini, F. 1990. Indagini etnobotaniche in Sicilia. I. Le piante della flora locale nella tradizione locale delle Madonie (Palermo). Naturalista siciliano, S. IV,XIV,3-4:77-99 (In Italian).

Raimondo, F.M. and Venturella, G. 1993. Lineamenti fisici e biogeografici del promontorio di Monte Pellegrino (PA). Quaderni Botanica Ambientale Applicata 4:711 (In Italian).

Schippmann, U., Leaman, D.J. and Cunningham, A.B. 2002. Impact of cultivation and gathering of medicinal plants on biodiversity: global trends and issues. In: FAO, 2002. Biodiversity and the Ecosystem Approach in Agriculture, Forestry and Fisheries. Satellite event on the occasion of the Ninth Regular Session of the Commission on Genetic Resources for Food and Agriculture, Oct. 12-13 2002. Inter-Departmental Working Group on Biological Diversity for Food and Agriculture, Rome 21p.

Vender, C. 2001. Indagine sulla consistenza e le caratteristiche della produzione di piante officinali in Italia. Dati 1999. Comunicazioni di ricerca ISAFA, Villazzano (TN, Italy), 2001/3:72p (In Italian). 